\section{Helicobacter Pylori in periodontal pockets of chronic periodontitis patients with and without type II diabetes mellitus: a randomized controlled trial}

\author{
Savita Sambashivaiah, Shivaprasad \\ Bilichodmath, Nanjammanni Nanjaiah, \\ Rithesh Kulal
}

Department of Periodontology, Rajarajeswari Dental College and Hospital, Bangalore, Karnataka state, India

\section{Abstract}

This randomized controlled study evaluated the association of Helicobacter pylori ( $H$. pylori) with chronic periodontitis patients with and without type II Diabetes Mellitus. $H$. pylori is considered to be a pathogen responsible for gastritis, peptic ulcers and a risk factor for gastric cancer. The aim of the present study was to evaluate the association of $H$. pylori with chronic periodontitis patients with and without type II diabetes mellitus before and after treatment. The prevalence of $H$. pylori in periodontal pockets was determined by rapid urease test in a 36 patients, which were grouped as Group 1 (Healthy subjects), Group II (chronic periodontitis patients) and Group III (Chronic periodontitis patients with Type II Diabetes Mellitus), 12 in each group before treatment by collecting plaque samples. After treatment, 12 plaque samples were collected and prevalence $H$. pylori was detected. Group II and Group III had a significantly higher rate of positive results for $H$. pylori compared to healthy subjects before treatment. After treatment, $H$. pylori were not detected in Group II and in Group III Only one of 12 chronic periodontitis patients with Type II diabetes mellitus had $H$. pylori in the periodontal pocket. The prevalence of $H$. pylori did not differ significantly between the chronic periodontitis patients with and without type II diabetes mellitus. Meticulous scaling and root planning will reduce the prevalence of $H$. pylori in periodontal pockets.

\section{Introduction}

Helicobacter pylori (H. pylori) is a curved, spiral, or gull-wing shaped microaerophilic, Gram- negative, motile bacterium with polarsheathed flagellae. H. pylori is considered to be a pathogen responsible for gastritis, peptic ulcers and a risk factor for gastric cancer. ${ }^{1-5}$

The mode of transmission of $H$. pylori is poorly understood, although the oral-oral, gastric-oral and fecal-oral routes are possible. ${ }^{6}$ The detection of this microorganism in the oral cavity has been reported by several groups, ${ }^{7-15}$ who demonstrated the microorganism in dental plaques and saliva, which would implicate the oral cavity as a potential reservoir for $H$. pylori or a possible route of transmission to other sites. However, other studies reported no detection of $H$. pylori from dental plaque samples. ${ }^{16-20}$ Umeda et al. compared the prevalence of $H$. pylori in patients with and without periodontal pockets and showed a higher prevalence of the bacteria in patients with deep periodontal pockets. ${ }^{21} \mathrm{H}$. pylori has ability to co-aggregate with periodontopathogenic bacteria such as Fusobacterium nucleatum and Porphyromonas gingivalis. ${ }^{22}$

Diabetes mellitus (DM) is complex metabolic disorder, characterized by chronic hyperglycemia. A multivariate risk analysis showed that subjects with type II DM had approximately 3 fold increased odds of having periodontitis and having altered flora in the periodontal pockets of patients with diabetes. ${ }^{23,24}$ Many studies have evaluated the prevalence of $H$. pylori infection in diabetes patients with gastritis and the possible role of this condition in glycemic control. ${ }^{25}$ Therefore the aim of the present study was to evaluate the association of $H$. pylori with chronic periodontitis patients with and without type II diabetes mellitus before and after treatment. According to our knowledge this is the first study being carried out in this regard.

\section{Materials and Methods}

The study population was selected randomly from patients attending the Department of Periodontology, Rajarajeswari Dental College and Hospital, Bangalore from April to June 2010. The grouping was as follows:

Group I: 12 Healthy subjects;

Group II: 12 Chronic periodontitis patients;

Group III: 12 Chronic periodontitis patients with Type II Diabetes Mellitus.

12 plaque samples from healthy subjects ( 9 males and 3 females, mean age $22.58 \pm 4.95)$, 12 plaque samples from group II ( 6 males and 6 females, mean age $40.57 \pm 12.41$ ) and 12 from group III (10 males and 2 females, mean age $48.67 \pm 8.31$ ) were collected before the periodontal treatment. Twelve samples each were collected from group II and group III after treatment.

Chronic periodontitis was diagnosed using the periodontal disease classification system of
Correspondence: Shivaprasad Bilichodmath, Department of Periodontology, Rajarajeswari Dental College and Hospital, Bangalore, Karnataka state, India.

E-mail: drshivaprasad2008@yahoo.co.in

Key words: H. Pylori, type II diabetes mellitus, chronic periodontitis, rapid urease test.

Contributions: the authors contributed equally.

Conflict of interest: the authors report no conflicts of interest.

Received for publication: 14 June 2011.

Revision received: 25 July 2011.

Accepted for publication: 6 August 2011.

This work is licensed under a Creative Commons Attribution NonCommercial 3.0 License (CC BYNC 3.0).

(C) Copyright S. Sambashivaiah et al., 2011

Licensee PAGEPress, Italy

Microbiology Research 2011; 3:e12

doi:10.4081/mr.2011.e12

the American Academy of Periodontology (1999). ${ }^{26}$ Chronic periodontitis patients with minimum of 20 teeth and average probing depth of $>5 \mathrm{~mm}$ with and without history of Type II diabetes mellitus were included in the study. Subjects with healthy periodontium were defined as having probing depth of $<3 \mathrm{~mm}$ and gingival index of $1 \mathrm{~mm}$. The known cases of type II DM in group III were assessed by random blood sugar level (RBS) and questionnaire. Exclusion criteria were as follows: any history of chronic gastritis, smoking, pregnancy, and periodontal therapy within last 6 months, other systemic conditions that could affect the periodontal status, use of local or systemic antimicrobial agents within 6 months prior to entry into the study. Periodontal evaluation included the Gingival Index (GI) ${ }^{27}$ and the probing pocket depth (PPD). Ethical clearance for the study was obtained from Institutional Ethical Review Board and subjects who satisfied the inclusion criteria of the study were selected. Informed consent was obtained from all enrolled individuals.

\section{Collection of samples}

Supragingival plaque was removed with sterile gauze and subgingival plaque samples were collected from deepest pocket in patients with chronic periodontitis with and without type II DM using sterile curettes. In healthy subjects plaque samples were collected from random sites. Subjects with chronic periodontitis with or without type II DM received full mouth scaling and root planing under local anesthesia and instruction in proper home care procedure and recalled after 2 weeks for post treatment sample collection. 


\section{The rapid urease test}

Presence of H.pylori in the samples was detected by rapid urease test. Samples were transferred immediately into vial containing rapid urease test reagent. If the test solution color was changed from yellow to pink within 30 min (as recommended by the manufacturer), the sample was considered to be positive for $H$. pylori.

\section{Statistical analysis}

Descriptive statistical analysis has been carried out in the present study. Results on continuous measurements are presented on Mean \pm SD (Min-Max) and results on categorical measurements are presented in Number (\%). Significance was assessed at 5\% level of significance. $\chi^{2} /$ Fisher Exact test was used to find the significance of study parameters on categorical scale between two or more groups. 95\% confidence interval was computed to find the significant features.

\section{Results}

The demographic and clinical parameters of the subject groups are shown in Table 1 . Clinical parameters (PPD and GI) was found to be significantly greater in the Group II and Group III when compared to Group I $(\mathrm{P}<0.01$; Chi-square test). The significant differences were observed between the groups with respect to gender and age.

The presence of $H$. pylori in periodontal pockets was determined by rapid urease test and result was expressed as either positive or negative. Five out of 12 subjects (41.71\%) in group I, 9 out of 12 subjects (75\%) in Group II and 10 out of 12 subjects (83.3\%) in Group III revealed positive rapid urease test results before treatment. Figure 1 shows the detection rate of $H$. pylori among the groups by rapid urease test before treatment. The difference in incidence of $H$. Pylori in group III (83.3\%) and group II (75\%) was statistically significant (Chi-square test, $\mathrm{P}=0.001$ ). Figure 2 shows the prevalence of $H$. pylori in the subgingival plaque of Group II after treatment and Group III after treatment patients. $H$. pylori was not detected in Group II patients after treatment but was present in only one out of 12 patients of group III after treatment.

\section{Discussion}

The periodontal pocket may provide a conducive environment for the colonization of $H$. pylori. The complex and diverse microbiota together with persistent inflammatory process may provide a wide range of nutrients and binding site for the establishment of this microorganism. Closely related species such as Campylobacter rectus ${ }^{28}$ and Fusobacterium ${ }^{29}$ were described as key microorganism in the process of co-aggregation among different genera of facultative bacteria. Colonization of these species may favour the establishment of H. pylori in the periodontal environment. Moreover, the subgingival biofilm can provide significant amount of urea, which can favour the urease-producing bacteria, such as $H$. pylori. Antagonistic relationship also may occur within subgingival biofilm.

The present study was undertaken to evaluate the association between $H$. pylori and chronic periodontitis with and without type II diabetes mellitus in 36 subjects before and after treatment. There was increased prevalence of $H$. pylori in Group II and Group III patients before treatment as compared to periodontally healthy subjects (Group I). The results of the present study suggest the possible association of $H$. pylori with chronic periodontitis with and without type II diabetes mellitus. Riggio and Lennon studied the presence of $H$. pylori in the subgingival plaque of adult periodontitis patients. They found that $38 \%$ of the subjects with deep periodontal pockets were positive for $H$. pylori.$^{30}$ Also, a study had suggested that poor periodontal health characterized by deep periodontal pock-

Table 1. Demographic and full-mouth clinical parameters (mean $\pm S D)$ of Group I, Group II and Group III subjects.

\begin{tabular}{lccc} 
Parameters & $\begin{array}{c}\text { Group I } \\
(\mathrm{n}=12)\end{array}$ & $\begin{array}{c}\text { Group II } \\
(\mathrm{n}=12)\end{array}$ & $\begin{array}{c}\text { Group III } \\
(\mathrm{n}=12)\end{array}$ \\
Age (years) & $22.58 \pm 4.95$ & $40.57 \pm 12.41$ & $48.67 \pm \pm 8.31$ \\
Males (\%) & 75.0 & 50.0 & 83.3 \\
\hline Females (\%) & 25.0 & 50.0 & 16.7 \\
Gingival index & $0.32 \pm 0.33$ & $1.80 \pm 0.34$ & $1.83 \pm 0.29$ \\
\hline PPD (mm) & $1.33 \pm 0.33$ & $7.91 \pm 0.91$ & $8.08 \pm 1.31$ \\
\hline
\end{tabular}
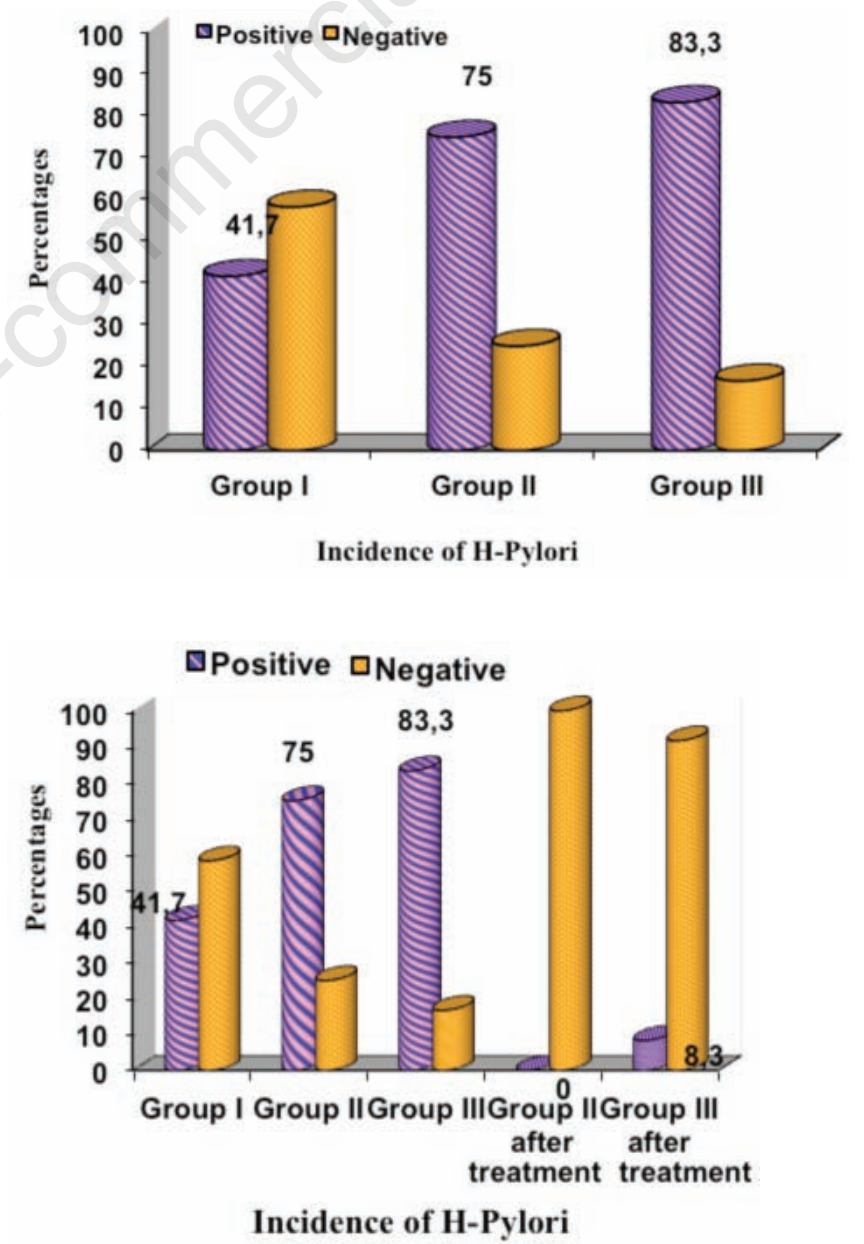

Figure 1. Rapid urease test results of $H$. pylori before treatment.
Figure 2. Preva lence of $H$. pylori after the treatment. 
ets may be associated with $H$. pylori infection ${ }^{31}$ and increased detection of the $H$. pylori in the oral cavity of the patients with periodontal disease and other oral conditions. The gender distribution reveals that $H$. pylori was detected more in males than in females; the role of the gender as a risk factor for $H$. pylori infection was not substantiated. High prevalence of $H$. pylori in the dental plaque has been reported using the Campylobacter-like organism (CLO) test and polymerase chain reaction (PCR). ${ }^{32-34}$ However, investigators have tried to detect by the culture method and reported that $H$. pylori was not cultivated from culture methods ${ }^{35}$ which may be due to low numbers of the organism in the dental plaque samples or existence of non-cultivable forms in the dental plaque. Other investigators employing PCR for the detection of $H$. pylori have also failed to reveal the specific amplification- product characteristic of $H$. pylori suggesting that periodontal pockets do not constitute a natural reservoir for H. pylori ${ }^{36}$ Also, high prevalence of H-pylori in the dental plaque and saliva has been detected using PCR in periodontitis patients. ${ }^{21}$ Studies have reported that rapid urease test has a specificity near $100 \%$ and sensitivity between $70 \%$ and $90 \%{ }^{37,38}$ The sensitivity of using this test on dental plaque to determine $H$. pylori status was reported to be $89.7 \%$, with diagnostic accuracy of $86.7 \% .^{39}$ It has been reported that other urease positive microoraganism present in the oral cavity such as Streptococcus vestibularis and Actinomyces viscosus usually cannot give positive results within an hour. ${ }^{40}$

Patients with diabetes mellitus are usually affected by chronic infections. Diabetic patients are at more risk for $H$. pylori infection in comparison to non-diabetic subjects. ${ }^{41}$ Some studies found a higher prevalence of $H$. pylori in diabetic patients and reduced glycemic control while others did not support any correlation between metabolic control and $H$. pylori infection. ${ }^{25}$ Black pigmented species, especially $P$. gingivalis, $P$. Intermedia and $C$. rectus, are prominent in severe periodontal lesion with type II diabetes. ${ }^{42,43}$ These results point to altered flora in the periodontal pockets of patients with diabetes. ${ }^{42}$ In the present study after the treatment, all the patients with chronic periodontitis (Group II) were negative for $H$. pylori and only one patient in Group III (with diabetes) was positive for $H$. pylori suggesting that meticulous scaling and root planning reduces the levels of $H$. pylori in periodontal pockets even in diabetes patients. This is the first study conducted to evaluate the association of $H$. pylori in chronic periodontitis patients with and without type II diabetes mellitus before and after treatment.

\section{Conclusions}

Periodontal pockets can act as reservoirs for H. pylori, which can interact with other periodontopathogenic bacteria and might potentially, participate in causing chronic periodontitis and chronic gastritis. The prevalence of $H$. pylori did not differ significantly between the chronic periodontitis patients with and without type II diabetes mellitus. Meticulous scaling and root planing can reduce the prevalence of $H$. pylori in periodontal pockets. Future studies with larger sample size involving other methods of detecting $H$. pylori like PCR and serology would help us to assess the potential role of $H$. pylori in periodontitis and possible transmission to cause chronic gastritis.

\section{References}

1. Dixon MF. Helicobacter pylori and peptic ulceration: Histopathological aspects. J Gastroenterol Hepatol 1991;6:125-30.

2. Graham DY. Helicobacter pylori: Its epidemiology and its role in duodenal ulcer disease. J Gastroenterol Hepatol 1991;6: 105-13.

3. Wotherspoon AC, Ortiz-Hidalgo C, Falzon $\mathrm{MR}$, Isaacson PG. Helicobacter pyloriassociated gastritis and primary B-cell gastric lymphoma. Lancet 1991;338:11756 .

4. Genta RM, Hamner HW, Graham DY. Gastric lymphoid follicles in Helicobacter pylori infection: Frequency, distribution, and response to triple therapy. Hum Pathol 1993;24:577-83.

5. Tytgat GN, Noach LA, Rauws EA. Helicobacter pylori infection and duodenal ulcer disease. Gastroenterol Clin North Am 1993;22:127-39.

6. Nguyen AM, EL-Zaatari FAK, Graham DY. Helicobacter pylori in the oral cavity. A Critical review of the literature. Oral Surg Oral Med Oral Pathol Oral Radiol Endod 1995;79:705-9.

7. Dowsett SA, Archila L, Segreto VA, et al. Helocobacter pylori infection in Indigenous families of Central America: Serostatus and oral and gingernail carriage. J Clin Microbiol 1993; 37:2456-2460.

8. Ferguson DAJ, Li C, Patel NR, et al. Isolation of Helicobacter pylori from saliva. J Clin Microbiol 1993;31:2802-4.

9. Lic C.Musich PR, Ha T, et al. High prevalence of Helicobacter pylori in saliva demonstrated by a novel PCR assay. J Clin Pathol 1995;48:662-666.

10. Mravak-Stiptetic M, Gall-Troselj K, Lukac J, et al. Detection of Helicobacter pylori in various oral lesions by nested polymerase chain reaction (PCR). J Oral Pathol Med 1998;27:1-3.

11. Dore-Davin C, Heitz M, Yang $\mathrm{H}$, et al. Helicobacter pylori in the oral cavity reflects handling of contaminants but not gastric infection. Digestion 1999;60:196202.

12. Song Q, Lange T, Spahr A, et al. Characteristic distribution pattern of Helicobacter pylori in dental plaque and saliva detected with nested PCR. J Med Microbiol 2000;5:30-7.

13. Miyabayashi H, Furihata K, Shimizu T, et al. Influence of oral Helicobacter pylori on the success of eradication therapy against gastric Helicobacter pylori. Helicobacter 2000;5;30-7.

14. Mapstone NP, Lynch DA, Lewis, et al. Identification of Helicobacter pylori DNA in the mouths and stomachs of patients with gastritis using PCR. J Clin Pathol 1993;46:540-3.

15. Jaskowski TD, Martins TB, Hill HR, Litwin, CM. Immunoglobulin A antibodies to Helicobacter pylori. J Clin Microbiol 1997;35:2999-3000.

16. Krajden S, Fuksa M, Anderson J, et al. Examination of human stomach biopsies, saliva, and dental plaque for Campylobacter pylori. J Med Microbiol 1989;27:1397-8.

17. Bickley J, Owen RJ, Fraser AG, Pounder RE. Evaluation of the polymerase chain reaction for detecting the urease $\mathrm{C}$ gene of Helicobacter pylori in gastric biopsy samples and dental plaque. J Med Microbiol 1993;39:338- 44.

18. Asikainen S, Chen C, Slots. Absence of Helicobacter pylori in subgingival samples detemined by polymerase chain reaction. Oral Microbiol Immunol 1994;9:318-20.

19. Oshowo A, Gillan D, Botha A, et al. Helicobacter-pylori: The mouth, stomach, and gut axis. Ann Periodontol 1998;3:27680.

20. Shankaran K, Desai HG. Helicobacter pylori in dental plaque. J Clin Gastroenterol 1995;21:82-4.

21. Umeda M, Kobayashi H, Takenchi Y, et al. High prevalence of Helicobacter pylori by PCR in the oral cavities of periodontitis patients. J Periodontol 2003;74:129-34.

22. Ishihara K, Miura T, Kimizuka R, et al. Oral bacteria inhibit Helicobacter pylori hemagglutination by human salivary mucins. FEMS Microbiol Immunol 1990;2:12-127.

23. Shlossman M, Knowler WC, Pettitt DJ, Genco RJ. Type 2 diabetes mellitus and Periodontal diseases. J Am Dent Assoc 1990;12:532-6.

24. Emrich LJ, Shlossman M, Genco RJ. Periodontol diseases in noninsulin dependent diabetes mellitus. J Periodontol 
1991;62:123-31.

25. Ojetti V, Migneco A, Silveri NGet al. The role of $H$. pylori infection in diabetes. Curr Diabetes Rev 2005;1:343-7.

26. Armitage GC. Development of a classification system for periodontal diseases and conditions. Ann Periodontal 1999;4:1-6.

27. Loe H, Silness J. Periodontal disease in pregnancy. Acta Odontol Scand 1963;21:533- 51.

28. Socransky SS, Haffajee AD, Cugini MA, et al. Microbial complexes in subgingival plaque. J Clin Periodontol 1998;25:134-44.

29. Andersen RN, Ganeshkumar N, Kolenbrander PE. Helicobacter pylori adheres selectively to Fusobacterium spp. Oral Microbiol Immunol 1998;13:51-4.

30. Riggio MP, Lennon A. Identification by PCR of Helicobacter pylori in subgingival plaque of adult periodontitis patients. $\mathrm{J}$ Med Microbiol 1999;48:317-22.

31. Dye BA, Kruszon-Moran D, McQuillan G. The relationship between periodontal disease attributes and Helicobacter pylori infection among adults in the United States. Am J Public Health 2002;92:180915.

32. Majmudar P, Shah SM, Dhunjibhoy KR,
Deasi HG. Isolation of Helicobacter Pylori from dental plaques in healthy volunteers. Indian J Gastroenterol 1990;9:271-2.

33. Avcu N, Avcu F, Beyan C, et al. The relationship betweeen gastric-oral Helicobacter pylori and oral hygiene in patiens with vitamin B12-deficiency anemia. Oral Surg Oral Med Oral Pathol Oral Radiol Endod 2001;92:166-9.

34. Song Q, Spahr A, Schmid RM, et al. Helicobcter pylori in the oral cavity: High prevalence and great DNA diversity. Dig Dis Sci 2000;45:2162-7.

35. Von Recklinghausen G, Weischer T, Ansorg $\mathrm{R}$, Mohr C. No culture detection of Helicobacter pylori in dental plaque. Zentralbl Bakteriol 1994;281:102-6.

36. Asikainen S, Chen C, Slot J. Absence of Helicobacter pylori in subgingival samples determined by polymerase chain reaction. Oral Microbial Immunol 1994;9:318-20.

37. McNulty CAM. Detection of Helicobacter pylori by the biopsy urease test. In: Rathbone BJ , Heatly RV, eds. Helicobacter pylori and Gastroduodenal Disease. Oxford: Blackwell Scientific; 1992. pp. 5859 .

38. Deltesre M, Burette A, Glupcaynski Y.
Rapid identification of Campylobacter pylori in gastric biopsies. In: Menge $\mathrm{H}$, Greyar M, Tytgot GNJ, eds. Campylobacter pylori. Berlin: Springer Verlag; 1988. pp. 135-144.

39. Gurbuz AK, Ozel AM, Yazgan Y, et al. Oral colonization of Helicobcter pylori: Risk factors and response to eradication therapy. South Med J 2003;96:244-7.

40. Vaira D, Holton J, Cairns S, et al. Urease test for Campylobacter pylori: Care in interpretation. J Clin Pathol 1988;41:8123 .

41. Devrajani BR, Shah SZ, Soomro AA, Devrajani T. Type 2 diabetes mellitus: A risk factor for Helicobacter pylori infection: A hospital based case-control study. Int J Diabetes Dev Ctries 2010;30:22-6.

42. Genco RJ, Shlossman M, Zambon JJ. Immunological studies of periodontitis patients with type II diabetes. J Dent Res 1987;66:257(abstract).

43. Zambon JJ, Reynolds H, Fisher JB, et al. Microbiological and immunological studies of adult periodontitis in patients with non-insulin dependent diabetes mellitus. J Periodontol 1988;59:23-31. 